\title{
Conspiratorial rationality
}

\section{Ott Puumeister ${ }^{1}$}

Review of Strategic Conspiracy Narratives: A Semiotic Approach [Series Conspiracy Theories; Knight, Peter; Butter, Michael, series eds.] by Mari-Liis Madisson and Andreas Ventsel. London: Routledge, 2020, x+134 pp.

\section{What became of the demos?}

The internet is a puzzling space. It is neither public nor private. Social media sites provide us with the opportunity to fashion ourselves into an online persona - which need not have anything to do with our offline self, engage in interaction with others and thus construct communities. In this sense, the internet is a socio-political space. However, it is also a space framed in terms of privacy, in which we are accustomed to behave as if it was our own home to which we have invited some friends. In this sense, it is a very personal and intimate space. Thirdly, of course, it is also a space which is largely owned by the so-called Big Five, the corporations Amazon, Apple, Alphabet, Facebook and Microsoft. Thus, no matter whether we conceptualize the internet as a political or a private space, it is, first and foremost, a place of business in which most of the information and data produced are employed to make a profit. It is, then, a space of "surveillance capitalism", which "claims human experience as free raw material for translation into behavioral data" (Zuboff 2019), based on which it is possible to predict consumer behaviour. Even though the internet is a space of politics and fashioning new communities, it is decidedly not a (deliberative) democratic one; rather, it is an 'advertising panopticon' (Bartlett 2018), which sells candidates and parties to people based on their previous online activity.

The hunt for profit and the transformation of behaviour and experience into data and information can be said to constitute the underlying logic for constructing the affordances of new media environments. That is, what can be done and how one can behave in digital environments is, to a large extent, determined by the pursuit

1 Department of Semiotics, University of Tartu, Jakobi 2, 51005, Tartu, Estonia; e-mail: ott. puumeister@ut.ee. 
of an increase in user base: a good - or an efficient - platform, smart device, etc. is that which cannot be put down, which demands that it be used constantly. One of the primary design processes through which the hooking of users is achieved is called 'gamification': the introduction of elements and features of games - competition, progression, affective engagement, etc. - into all types of interactions with others and with the world more generally. In short, it is "the process of making activities more game-like" (Werbach 2014: 266). Through this process, new media environments are made addictive, demanding that users constantly (re)turn to them in hopes of more success, yet another victory or progression to a next level.

It is no surprise, then, that social media and online environments more generally produce strong affective reactions and desires that people perhaps did not even realize were driving them. Interaction with and in social media is fuelled by desire. And this desire - via transformation into quantifiable data and information - earns large amounts of money for the corporations that own significant parts of the internet. The-turn-of-the-century utopian dream of the internet as a space of liberation and as a birthplace of new democratic communities has vanished and been replaced by the pursuit of gratification of insatiable desires. The promised demos 2.0 has dissolved into malleable data points.

It would seem, then, that something like Habermasian 'communicative rationality' is downright impossible in the contemporary social media environment which construes other users not as people, but as means towards an end. People have become means in a twofold sense. Firstly, as sources of marketable data, and secondly, as competitors of each other, obstacles in, or consumable objects for the gratification of desires. Insofar as social media encourages participation and interaction, it does so based on 'instrumental rationality'. This means that we are dealing not with communicative, but strategic action, to use Jürgen Habermas's terms. Communicative action, for Habermas, is directed towards understanding; strategic action, on the other hand, leans towards influencing and persuasion in order to achieve personal ends. The two are incompatible: "Seen from the perspective of participants, the two mechanisms - that of reaching understanding, which motivates convictions, and that of exertion of influence, which induces behavior must be mutually exclusive" (Habermas 1998: 221-222).

Even though the two types of action are mutually exclusive, strategic action feeds off of communicative action and understanding: persuasion through deception would not be possible without the presupposition of truth. In order to be deceived, the addressee must believe the sender's lies. Thus communicative rationality is primary for Habermas, not only normatively, but in reality: strategic persuasion would not work without the presumption of truth (see Niemi 2005). This primacy of communicative action enables Habermas to posit that 
rationality - although it has made some missteps - still has the potentiality to save democracy and that it is something that should itself be saved and preserved (see Habermas 1984, 1987; d'Entrèves, Benhabib 1997).

Habermas, as a descendant and reformer of the critical theory of the Frankfurt School, was writing in an intellectual climate in which instrumental rationality using others as means to an end - was understood to be the grounding and guiding principle of political action. In addition, rationality or reason as it was known from the Enlightenment was declared if not dead, then at least catastrophically dangerous, most prominently by Adorno and Horkheimer (2002[1944]). Contemporary critical theorists have lost faith in the saving power of communicative rationality and stress the primacy of instrumental rationality and strategic action (e.g., Han 2019[2005]). Any sort of communication and interaction is traversed by power and is, thus, strategic. There can be no common ground for rational (democratic) deliberation.

\section{Conspiracy theories and politics}

The prominence of conspiracy theories in contemporary (online) culture seems to render Habermas's insistence on the primacy of communicative action over that of strategic action especially doubtful. Indeed, conspiracy theories can be said to be the quintessential form of strategic communication in that they are never directed towards understanding, but always aimed at influencing the addressee into believing an (oftentimes outrageously) false image of the world and into behaving according to these beliefs. If there is one kind of knowledge that can with confidence be called 'unjustified false belief', it is the conspiratorial kind.

Conspiratorial rationality - the belief in an evil group of people governing the state of the world - cannot be fact-checked away. Fact checks do not make those disseminating, constructing and consuming conspiracy narratives waver: unlike scientific evidence, evidence operating in conspiracy theories is presumed to be absolutely certain, and thus irrefutable - it is not falsifiable, for even the absence of evidence points towards the success of the conspiracy. Think of the connection between President of the United States Donald Trump, and the ridiculously grand-scale QAnon conspiracy. ${ }^{2}$ Conspiracy theories have found their place in mainstream politics, notwithstanding the overwhelming (scientific, journalistic, political, etc.) evidence against their truth claims.

2 See https://www.theguardian.com/us-news/2020/aug/02/qanon-conspiracy-theoryrepublican-party-candidates; https://www.theguardian.com/us-news/2020/aug/23/donaldtrump-qanon-conspiracy-theory. 
However, this should not come as a surprise, because the conspiracy theory is, first and foremost, a type of political speech act. Conspiracies and conspirators have, of course, always had a significant role to play in European politics and power play, starting from Ancient Greece and Rome. As Joseph Roisman (2006: 1) puts it in his reading of the Attic orators, it seems that secret plots traversed "almost every facet of Athenian life" and that people from almost all social positions were involved in plotting. And, at least in the case of Rome, it is also possible to speak of conspiracy theories as we would use the term today: "The fear of women, slaves, or even foreigners conspiring against Rome persists from the legendary days of the seven kings until confirmed by the foreign invasions leading to the empire's collapse. By the time of the late Republic, Roman writers had already begun to cash in on the negative stereotypes of these marginalized groups by casting them as conspirators" (Pagán 2008: 32). The image of women as conspirators extends from Roman popular comedy to the history of Livy; thus, it cannot be said to be marginal, but rather to constitute a popular stereotype instead. In a society ruled by men (and it is largely the texts of this elite that historians have as sources), it was, of course, the women who attempted to subvert the rule(s)...

Thus, the political-strategic and identificational logic of conspiracy theories, which is also at the centre of Mari-Liis Madisson's and Andreas Ventsel's book Strategic Conspiracy Narratives: A Semiotic Approach (henceforth, SCN), could already be glimpsed in Ancient Rome. SCN, however, stresses the novelty of the contemporary situation, stating that although "bursts of conspiracy theories have been detected as having occurred in culture centuries ago (e.g., the witch hunts of the seventeenth century - see Lotman 2007), it can be claimed with certainty that never before in history have so many people been simultaneously informed about versions of particular conspiracy theories as in this day and age of social media" (Madisson, Ventsel 2020: 32). Of course, the book's focus is very much on the contemporary, but it would have perhaps been beneficial - in order to gain a wider perspective and context - to go beyond a single historical reference to witch hunts. This move risks overstating the unprecedented nature of our socio-political situation. Still, it does not undermine the analysis and theoretical conceptualization presented in SCN.

The very definition of a conspiracy theory casts it as a strategic tool rather than a proposition subject to rules of verification. One of the most comprehensive definitions is provided by Brian Keeley (1999: 116): "A conspiracy theory is a proposed explanation of some historical event (or events) in terms of the significant causal agency of a relatively small group of persons - the conspirators - acting in secret." It thus presumes a guilty party that can be blamed for even the most unlikely of events. As Madisson and Ventsel also point out, conspiracy 
theories often emerge in contexts of crisis in which people have no explanations for the ills that have befallen them.

The guilty party - the scapegoat - is, of course, a political enemy rather than somebody actually having something to do with the events "explained", while the infallible certainty of the theory is also, first and foremost, political. What must be drawn with absolute certainty are the boundaries of the political community, that is, the boundaries between 'us' and 'them'; if 'they' are guilty of 'our' misfortunes, 'they' should and will be acted against. Political discourse, as Bruno Latour (2003) has stressed, is not about veracity and falsity, but about constructing and delimiting communities: who are with us, who are against us, even who is this 'us', etc. The amount of lies told by a politician does not matter if s/he lies appropriately, that is, to the liking of his or her community, confirming their political identities.

Thus, it seems that there is very little separating political discourse and conspiracy theories. The latter have been operating in the political process of Europe for a very long time already and are primarily a means of drawing the boundaries of communities. This tight and inseparable connection is seen - in a perhaps inadvertent, but nevertheless telling misattribution - also in SCN, where the authors conceptualize conspiracy theories through Ernesto Laclau and Chantal Mouffe: "[W]e can conceptualise the conspiracy theory as a process of meaning-making whose objective is "the transformation of a social relation which constructs a subject in a relationship of subordination" (Laclau, Mouffe 1985, 153; see also Laclau 1990, 172; Marchart 2007, Ch. 2) [...]" (p. 38). Laclau and Mouffe (1985: 153) spoke, in actuality, of the "political' character" of social struggles more generally; they attempted to define what it is that turns a social struggle into a political one. In failing to point out this difference of perspective, SCN risks confounding political struggle with conspiracy theories - and casts prominent philosophers of 'the political' (along with Laclau and Mouffe, also Oliver Marchart) as philosophers of conspiracy theories. Indeed, for both political struggle and conspiracy theories, constructing a position of the victim is indispensable - only those who have been wronged somehow, have the right to speak up and take action. Yet how, then, should we distinguish between the operative logic underlying political discourse and conspiracy theories?

One possibility is to stress that the difference between the political character of social struggles and conspiracy theories is that the latter are often tools in the hands of the political elite - those who already govern or who aspire to attain a position in government. This is apparent from Ancient Rome through the early modern witch trials and Nazi anti-Semitism campaigns to contemporary European and American political parties. SCN clearly makes this point (Madisson, Ventsel 2020: 42): conspiracy theories should not be viewed primarily as responses to power 
by the less powerful, but also as strategic tools in the hands of the powerful (from state governments to large corporations) with which to persuade people to vote for them, consume their products, and show aggression towards those others, the scapegoats. Thus, conspiracy theories as speech acts perform a very particular sort of politics, one which casts the enemy as a wrongdoer that should be ostracized or eliminated, even though this "enemy" is often already an outcast or a marginalized group of people [think of migrants, women (as witches), LGBTQIA+ people, etc.]. Even though the principal villain of conspiracy theories can be powerful - as in the case of George Soros, analysed in SCN, or political elites more generally -, the pointy end of these theories is more often than not aimed at rather helpless and vulnerable groups.

\section{Strategic narratives, or how to do things with words}

This perspective - conspiracy theories as strategic narratives - is especially useful in that it, firstly, enables us to refrain from understanding contemporary digital natives as inherently stupid and gullible, as clueless automatons whose mind can be controlled by flashing notifications on screens. Secondly, it enables us to go beyond posing questions about the veracity or falsity and rationality or irrationality of conspiracy theories. SCN's perspective, although it uses the framework of semiotics of culture and meaning-making, rather deals with the question of how conspiracy theories function than with what they mean. It is, then, an inherently pragmatic perspective which is concerned with meaning insofar as it operates in intersubjective practice, in communication. Thus, it represents a socio-semiotic perspective, although stemming from the vocabulary of Juri Lotman's semiotics of culture. In this perspective, then, it is possible to see that a semiotics based on the concept of text and on textual analysis can be employed in socio-political analysis of communicative practice.

In attempting the analysis, the major problems the authors face are posed by the domain studied - digital online environments. Within these environments, both the sender and the receiver are often invisible. They cannot be reached. What can be observed are single texts - in the general semiotic sense of text as a bounded meaningful unit, and not necessarily in the sense of verbal texts - from which larger conspiracy theories are compiled, the distribution and dissemination of these texts via shares, the popularity of the texts via likes and comments, etc. Of course, it would be possible to say that it is the minds of the receivers that can be reached via likes, shares, comments, etc., but this means forgetting that - however physical the consequences of online communication might be - often the person 
typing the comments and sharing the information might not even be a person, or may be a cynical troll. For this reason, digital ethnography cannot limit itself to the surface-level activity visible on platforms and social media sites.

These problems, however, are solved (or bypassed) to an effective degree, using the concept of the strategic narrative - defined in SCN through Miskimmon, O'Loughlin and Roselle (2017: 6) as "a means by which political actors attempt to construct a shared meaning of the past, present, and future of international politics to shape the behaviour of domestic and international actors" (Madisson, Ventsel 2020: 4) - and Umberto Eco's (2005) concept of the Model Reader "that allows the researcher to study which semiotic strategies have been used in constructing the audiences targeted in the strategic conspiracy narratives" (Madisson, Ventsel 2020: 4). SCN looks, firstly, for a coherent narrative with aims that are potentially beneficial for certain political actors, and, secondly, for an idealized potential reader constructed within the text(s). SCN speaks, thus, of a Model Author, for whom the outcome of a strategic narrative is beneficial, and of a Model Reader, whose tracing of the interpretive paths laid out by the Model Author would also be beneficial for the latter. The unity of the narrative and the concurrence between the Model Author and Model Reader are sought in a conflict, which fixes the opposing sides and thus also constructs a collective identity for them. Conflict is understood as "the strategic core of conspiracy theories" (Madisson, Ventsel 2020: 5). Through conflict - articulation of the figures of evil conspirators and their collaborators as those 'we' should be fighting against - a political identity is constructed, and by disseminating textual evidence of this conflict in digital environments this identity is constantly being reproduced.

It is not surprising to learn that these conflicts are already very old and have by no means been created by novel digital technologies (e.g., natives vs. migrants; natives vs. "cosmopolitan Jews"; majority vs. minorities; "conservatives" vs. "cultural Marxists", etc.). Digital online environments, however, are very good at delivering messages to the right people, and keep doing this constantly and incessantly. Drawing on Roman Jakobson, SCN speaks of phatic communication here, and identifies this function as the dominant in online communicative practices: "In connection with identity formation, the discourse of conspiracy theories displays its specific function confirming social ties. The semantic value of information transmitted by conspiracy theories is relatively minimal" (Madisson, Ventsel 2020: 39). That is, textual evidence of conspiracy theories, and messages spreading them, works on people who are already liable to believe in the theories, for instance those who are already aligned with the "native population" against the "migrants". Conspiracy theories rarely say anything new, even the most recent ones (the most extensive and popular of which is probably QAnon) mainly rehash 
and remix conflicts from old conspiracy theories. So it would perhaps be more accurate to say that social media enables political actors to mobilize the right people - which is identified as one of the functions of conspiracy narratives in SCN -, more so than persuade new people.

At this point, we come back to the slightly conspiratorial opening of this review and to the Big Five of Amazon, Apple, Alphabet, Facebook and Microsoft, and their constant surveillance of online activity for profit-making. Through collecting and selling of these data it is possible to know which advertisements, which websites to send and recommend to exactly which kind of person. Surveillance activity by corporations is, of course, suspiciously similar to conspiratorial activity, and seems to be an appropriate context for the extremely wide popularity of conspiracy theories - within a conspiracy to attain a status of monopoly for the means of communication. Now, the question how and for what reasons these monopolistic practices attain legitimacy in our culture would be an interesting and relevant question for future studies of conspiracy theories, which would then take into account not only the overt political discourse, but also the economic and technological context which shapes the very possibility of our communication. As mentioned above, semiotics of culture has taken a pragmatic turn - although the authors do not conceptualize their work through pragmatism - in SCN via the concept of the strategic narrative. That is, the focus is on how things are done with words, what signs can accomplish in action and how their meaning arises out of their functioning in socio-political contexts. This perspective would seem to provide a groundwork for asking - and tackling - also these types of wider questions in the framework of the semiotics of culture.

Finally, the concept of strategic narrative enjoys a clear advantage over that of ideology, which has a rather similar meaning in that it answers questions of who we are, why we are doing the things we are doing, who are against us, etc. Through 'ideology', however, these constructions would be viewed as inherently skewed and false, and those whose thought operates in the context of a certain ideology would be viewed as dupes and victims (this despite the efforts to render ideology into a value-free concept - see Geertz 1973). Ideology implies that the believer in the system of (false) beliefs simply does not know better, and can thus be educated via non-ideological communication and information. However, as pointed out above, the primacy - and even the possibility - of rational non-ideological communication is not straightforward, and is rather a normative vision of Habermasian critical theory. Furthermore, it has long been clear that the forms of rationality in given socio-political contexts are themselves constructed with political interests in mind. This does not mean, of course, that we should take conspiracy theories seriously as acceptable models of the world; it simply means that we should stop 
treating people as if they were ignorant of their actions and thus stop taking them for fools - it is not a question of ideology, but of strategy. And this is an important point for political semiotics to keep in mind. As Michel Foucault once put it: "People know what they do; they frequently know why they do what they do; but what they don't know is what they do does" (Dreyfus, Rabinow 1982: 187). ${ }^{3}$

\section{References}

Adorno, Theodor W.; Horkheimer, Max 2002[1944]. Dialectic of Enlightenment: Philosophical Fragments. (Jephcott, Edmund, trans.) Stanford: Stanford University Press. https://doi.org/10.1515/9780804788090

Bartlett, Jamie 2018. The People vs Tech: How the Internet Is Killing Democracy (And How We Save It). New York: Random House.

d'Entrèves, Maurizio Passerin; Benhabib, Seyla (eds.) 1997. Habermas and the Unfinished Project of Modernity: Critical Essays on the Philosophical Discourse of Modernity. Cambridge: The MIT Press.

Dreyfus, Hubert L.; Rabinow, Paul 1982. Michel Foucault: Beyond Structuralism and Hermeneutics. Chicago: The University of Chicago Press. https://doi.org/10.7208/ chicago/9780226154534.001.0001

Eco, Umberto 2005[1979]. Lector in fabula. Tartu: Tartu University Press.

Geertz, Clifford 1973. Ideology as a cultural system. In: The Interpretation of Cultures: Selected Essays. New York: Basic Books, 193-233.

Habermas, Jürgen 1984. The Theory of Communicative Action. Vol. 1: Reason and the Rationalization of Society. (McCarthy, Thomas, trans.) Boston: Beacon Press.

Habermas, Jürgen 1987. The Theory of Communicative Action. Vol. 2: Lifeworld and System: Functionalist Reason. (McCarthy, Thomas, trans.) Boston: Beacon Press.

Habermas, Jürgen 1998. Actions, speech acts, linguistically mediated interactions, and the lifeworld. In: On the Pragmatics of Communication. Cambridge: The MIT Press, 215-256.

Han, Byung-Chul 2019[2005]. What is Power? (Steuer, Daniel, trans.) Cambridge: Polity.

Keeley, Brian L. 1999. Of conspiracy theories. The Journal of Philosophy 96(3): 109-126. https://doi.org/10.2307/2564659

Laclau, Ernesto 1990. New Reflections on the Revolution of Our Time. London: Verso.

Laclau, Ernesto; Mouffe, Chantal 1985. Hegemony and Socialist Strategy: Towards a Radical Democratic Politics. London: Verso.

Latour, Bruno 2003. What if we talked politics a little? Contemporary Political Theory 2: 143-164. https://doi.org/10.1057/palgrave.cpt.9300092

Lotman, Juri 2007. Hirm ja segadus: Esseid kultuurisemiootikast [Fear and Confusion: Essays on the Semiotics of Culture]. Tallinn: Varrak.

3 This publication was supported by PRG314 "Semiotic fitting as a mechanism of biocultural diversity: instability and sustainability in novel environments". 
Madisson, Mari-Liis; Ventsel, Andreas 2020. Strategic Conspiracy Narratives: A Semiotic Approach. London: Routledge. https://doi.org/10.4324/9780429020384

Marchart, Oliver 2007. Post-Foundational Political Thought: Political Difference in Nancy, Lefort, Badiou and Laclau. Edinburgh: Edinburgh University Press. https://doi.org/ 10.3366/edinburgh/9780748624973.001.0001

Miskimmon, Alister; O’Loughlin, Ben; Roselle, Laura 2017. Introduction. In: Miskimmon, Alister; O'Loughlin, Ben; Roselle, Laura (eds.). Forging the World: Strategic Narratives and International Relations. Ann Arbor: University of Michigan Press, 1-22. https:// doi.org/10.3998/mpub.6504652

Niemi, Jari I. 2005. Jürgen Habermas's theory of communicative rationality: The foundational distinction between communicative and strategic action. Social Theory and Practice 31(4): 513-532. https://doi.org/10.5840/soctheorpract200531424

Pagán, Victoria E. 2008. Toward a model of conspiracy theory for Ancient Rome. New German Critique 103: 27-49. https://doi.org/10.1215/0094033X-2007-017

Roisman, Joseph 2006. The Rhetoric of Conspiracy in Ancient Athens. Berkeley: University of California Press. https://doi.org/10.1525/california/9780520247871.001.0001

Werbach, Kevin 2014. (Re)defining gamification: A process approach. In: Spagnolli, Anna; Chittaro, Luca; Gamberini, Luciano (eds.). Persuasive Technology (Lecture Notes in Computer Science, International Conference on Persuasive Technology). Cham: Springer, 266-272. https://doi.org/10.1007/978-3-319-07127-5_23

Zuboff, Shoshana 2019. The Age of Surveillance Capitalism: The Fight for a Human Future at the New Frontier of Power. New York: Public Affairs. 